\title{
Características de carcaça, órgão vomeronasal, concentrações séricas de testosterona e IGF-I em machos Nelore com ductos incisivos bloqueados*
}

\section{Characteristics of carcass, vomeronasal organ, serum testosterone and IGF-I concentrations in Nellore males with blocked incisor ducts}

\author{
Lucas Luz Emerick, ${ }^{* *}$ Germán Arthuro Bohórquez Mahecha, ${ }^{* * *}$ Paulo Eduardo Machado Gonçalves, ${ }^{* * *}$ \\ Ticiano Guimarães Leite, ${ }^{* * * *}$ Jorge André Matias Martins, ${ }^{* * * * * *}$ Juliano Cesar Dias, ${ }^{* * * * * *}$ \\ Venício José de Andrade, ${ }^{* * *}$ Vicente Ribeiro do Vale Filho, ${ }^{* * * *}$ Afonso de Liguori Oliveira, ${ }^{* * * * * * *}$
}

\begin{abstract}
Resumo
Objetivou-se avaliar características quali - quantitativas da carcaça em machos Nelore, submetidos ao bloqueio dos ductos incisivos no período pré puberal. Além disso, objetivou-se avaliar as concentrações séricas de testosterona e do hormônio do crescimento semelhante a insulina do tipo I (IGF-I), e a arquitetura histológica do órgão vomeronasal (OVN). Trinta e quatro machos, no período pré puberal, foram divididos em três grupos experimentais: inteiros - animais controle sem qualquer procedimento ( $\mathrm{n}=$ 11); bloqueados - animais com os ductos incisivos bilateralmente obstruídos ( $n=10)$; castrados - animais com orquiepididectomia bilateral $(n=13)$. O OVN foi obtido no abate, ao final do experimento, para avaliação histomorfométrica. As coletas de sangue foram realizadas a cada três meses, em dois turnos (manhã e tarde), totalizando cinco avaliações. Observaram-se maiores $(P<0,05)$ pesos corporais finais (inteiros $=494,1 \pm 28,71$; bloqueados $=500,6 \pm 23,6$ e castrados $=468,3 \pm 21,8 \mathrm{Kg}$ ) nos inteiros e bloqueados. O acabamento da carcaça foi maior nos castrados $(\mathrm{P}<0,05)$ em relação aos inteiros e bloqueados, enquanto o rendimento de carcaça não apresentou diferenças entre os três tratamentos $(P>0,05)$. Registrou-se redução da altura do epitélio neuro sensitivo do OVN nos bloqueados e castrados $(\mathrm{P}<0,05)$. Foi registrada menor concentração de testosterona nos bloqueados nas coletas quatro e cinco à tarde $(\mathrm{P}<0,05)$. Conclui-se que a obstrução dos ductos incisivos reduziu os estímulos sensoriais para o OVN, que por sua vez, promoveu alteração na concentração sérica de testosterona, sem alterar o ganho de peso dos animais, porém, não promoveu melhoria na qualidade da carcaça nas condições deste estudo.
\end{abstract}

Palavras-chave: Bos taurus indicus, bulbo olfatório acessório, cobertura de gordura na carcaça, ganho de peso médio diário

\begin{abstract}
A total of 34 prepuberal Nellore males were divided into three groups: control - animals without any procedure $(\mathrm{n}=11)$; blocked with bilaterally incisors ducts obstructed $(n=10)$; castrated - with bilateral orchiectomy $(n=13)$. This study aimed to evaluate the effect of blocking the vomeronasal organ (VNO) in qualitative and quantitative characteristics of the carcass. Also, this study aimed to evaluate testosterone and insulin-like growth factor (IGF-I) serum concentration, and the histological architecture of the OVN. Blood samples were taken every three months during two daily collections (morning and afternoon), totalizing five evaluations. It was observed higher $(P<0.05)$ final body weight $($ control= $494.1 \pm 28.71$; blocked $=500.6 \pm 23.6$; castrated $=468.3 \pm 21.8 \mathrm{~kg}$ ) at the control and blocked groups. Carcass finishing was higher in castrated animals $(P<0.05)$, while carcass yield did not differ between treatments $(P>0.05)$. It was observed a reduction $(P<0.05)$ of the VNO sensory epithelium height in blocked and castrated groups compared with control group. It was registered lower $(P<0.05)$ serum testosterone concentration in blocked group at the fourth and fifth blood collection (afternoon). It was concluded that the obstruction of the incisive ducts reduced the sensorial stimuli for the OVN, which, in turn, promoted a change in the serum concentration of testosterone, without altering the weight gain of the animals, but did not promote improvement in the quality of the carcass under the conditions of this study.
\end{abstract}

Keywords: accessory olfactory bulb, average daily gain, Bos taurus indicus, fat thickness.

*Recebido em 15 de outubro de 2018 e aceito em 30 de setembro de 2019.

**Universidade Federal Rural da Amazônia, campus Parauapebas, departamento de Zootecnia, Parauapebas, PA, Brasil. Autor para correspondência: lucaslemerick@yahoo.com.br;

***Universidade Federal de Minas Gerais (UFMG), Instituto de Ciências Biológicas, Belo Horizonte, MG, Brasil;

****Escola de Veterinária da UFMG, departamento de Zootecnia, Belo Horizonte, MG, Brasil;

*****Escola de Veterinária da UFMG, departamento de Clínica e Cirurgia Animal, Belo Horizonte, MG, Brasil;

******Universidade Federal Rural do Pernambuco, departamento de Zootecnia, Serra Talhada, PE, Brasil;

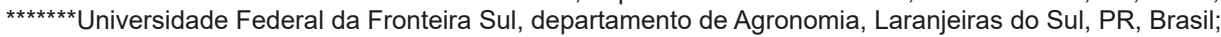

${ }^{* * * * * * * *}$ Escola de Veterinária da UFMG, departamento de Tecnologia e Inspeção de Produtos de Origem Animal, Belo Horizonte, MG, Brasil; 


\section{Introdução}

A castração é uma técnica empregada em bovinos de corte que busca a redução abrupta da concentração dos andrógenos circulantes, visando a obtenção de animais dóceis que alcancem o ponto ideal de abate. Isso propicia melhor acabamento de carcaça com boa distribuição de gordura superficial, características estas valorizadas pelo mercado (Padua et al., 2003).

No entanto, a castração ocasiona gastos com medicamentos e mão de obra em decorrência do procedimento cirúrgico e menor peso ao abate e redução na eficiência alimentar (Restle et al., 1996), atribuídas a diminuição da testosterona sérica (Rotta et al., 2009; Smith e Saunders, 2011). Essas desvantagens impedem a adoção plena da técnica como alternativa para aumento da produção de carne. Portanto, na tentativa de obter adequados desenvolvimento ponderal e acabamento de carcaça satisfatório têm sido propostas técnicas menos invasivas e moduladoras da concentração de testosterona (Gökdal et al., 2010).

O touro Nelore apresenta alta frequência do evento sexual de reflexo de Flehmen em testes de comportamento sexual (Lopes et al., 2009). Levando em consideração que este comportamento é um mecanismo facilitador na condução de feromônios sexuais para o órgão vomeronasal (OVN) (Vyas et al., 2012), e ainda que este órgão influencia a secreção de $\mathrm{GnRH}$ e testosterona em outras espécies (Keverne, 2004), sugere-se que o OVN exerça importante função na ativação do comportamento sexual e secreção de testosterona em animais Bos taurus indicus.

O órgão vomeronasal (OVN) é uma estrutura tubular quimioreceptora do sistema olfatório acessório responsável pela detecção de feromônios sexuais. Este órgão localiza-se na base do septo nasal e se comunica com a cavidade oral por meio do ducto incisivo (Baum e Cherry, 2015). Além disso, o OVN possui epitélio quimiorreceptor, que se associa ao eixo hipotalâmico-hipofisário-gonadal, influenciando a liberação de $\mathrm{GnRH}$. Contudo, a associação do OVN na secreção de esteroides depende de experiência sexual prévia do animal (Keverne, 2004).

O fator de crescimento semelhante a insulina - I (IGF-I) é um importante hormônio metabólico com funções no desenvolvimento sexual de ruminantes, estando associado com ganho de peso corporal e cobertura de gordura na carcaça (Brito et al., 2007), indicando que a avaliação sérica deste hormônio seja um método mais sensível para detectar qualquer alteração no balanço energético ou cobertura de gordura na carcaça do animal.

Diante do exposto, a hipótese desse estudo é que o bloqueio do OVN pela obstrução dos ductos incisivos module a concentração sérica de testosterona, sem afetar o ganho de peso dos animais, mas, ao mesmo tempo, acarretando em melhorias no acabamento e rendimento de carcaça, devido a maior deposição de gordura.

Dessa forma, objetivou-se com este avaliar as características quali - quantitativas da carcaça, a arquitetura histológica do OVN, a concentração sérica de testosterona e IGF-I em machos Nelore, submetidos ao bloqueio dos ductos incisivos no período pré puberal.

\section{Material e Métodos}

O presente estudo foi conduzido durante os meses de janeiro de 2008 e maio de 2009 na Fazenda Santo Antônio das Granjas Reunidas, município de Engenheiro Navarro, norte do estado de Minas Gerais-Brasil, situada numa região de Cerrado, com clima quente e úmido. A temperatura máxima e mínima foi de 30,8 e $17,2^{\circ} \mathrm{C}$, precipitação pluviométrica média anual 1063 $\mathrm{mm}^{3}$, altitude de $652 \mathrm{~m}$, latitude de $17^{\circ} 17^{\prime} 43^{\prime \prime} \mathrm{S}$ e longitude de $43^{\circ} 56^{\prime} 6^{\prime \prime} \mathrm{W}$.

Foram utilizados 45 machos da raça Nelore pré púberes com idade média de 14,6 $\pm 1,15$ meses, peso corporal médio de $244,2 \pm 13,4 \mathrm{Kg}$ e circunferência escrotal média de $20,5 \pm 1,4$ $\mathrm{cm}$ no início do experimento. Estes animais foram criados em regime de pastejo rotacionado e mantidos em grupos separados em piquetes homogêneos de cinco hectares, sendo revezados semanalmente entre estes. Durante o período seco, os animais foram mantidos em pastagens de Brachiaria brizantha irrigadas. A carga animal utilizada para os dois períodos foi de duas unidades animal por hectare.

Os animais foram divididos em três grupos com 15 animais. Ao final do estudo, alguns animais foram descartados por problemas de perda de peso e padrão racial nos primeiros 30 dias após o início da fase experimental, ficando os grupos assim constituídos: Grupo 1: controle (inteiros) - 11 animais inteiros que não foram submetidos a nenhum procedimento; Grupo 2: bloqueados -10 animais que tiveram seus ductos incisivos bilateralmente obstruídos; Grupo 3: castrados - 13 animais orquiepididectomizados bilateralmente.

A castração cirúrgica foi realizada segundo o método da orquiepididectomia bilateral convencional (Padua et al., 2003). A obstrução dos ductos incisivos foi realizada bilateralmente por meio do óstio palatino mediante cauterização com termo cautério (Booth e Katz, 2000). Para realização do procedimento foi realizada a antissepsia utilizando álcool etílico a $70^{\circ}$ e nitrato de prata 1:1.000 no ducto incisivo e na parte rostral do palato. A anestesia local foi realizada infiltrando cinco mililitros de lidocaína a $2,5 \%$ ao redor da papila incisiva.

Após jejum de 12 horas de dieta sólida, os animais foram pesados mensalmente de janeiro a julho de 2008 utilizando balança eletrônica individual. Posteriormente, foram realizadas pesagens em setembro de 2008, fevereiro e maio de 2009. Foram registrados os ganhos médios diários (GMD) entre as avaliações e ao final do estudo, com base nos pesos iniciais e finais.

Para as análises séricas de testosterona e IGF-I foram inicialmente amostrados aleatoriamente sete animais de cada grupo. Após os devidos descartes, foram considerados para as análises seis animais para cada um dos grupos controle e castrados e quatro animais do grupo bloqueados.

As coletas de sangue foram realizadas nos períodos da manhã (sete horas) e tarde (17 horas), com os horários definidos de acordo com os picos diários e $1 / 2$ vida da testosterona (Barbosa et al., 1991).

As datas das coletas de sangue foram em 2008, nos meses

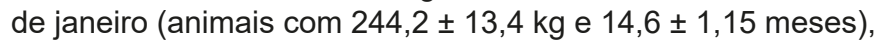
maio $(298,5 \pm 17,8 \mathrm{~kg}$ e $18,6 \pm 1,15$ meses), julho (328,4 $\pm 18,5$ 
kg e 20,7 $\pm 1,15$ meses) e outubro $(359,2 \pm 19,8 \mathrm{~kg}$ e $24 \pm 1,15$ meses) e fevereiro de 2009 (359,2 $\pm 19,8 \mathrm{~kg}$ e $24 \pm 1,15$ meses), totalizando cinco avaliações no total para cada grupo.

As amostras de sangue foram coletadas a vácuo por punção da veia jugular externa e posteriormente, centrifugadas a $300 \mathrm{~g}$ por 10 minutos para obtenção do plasma, que foi armazenado em nitrogênio líquido $\left(-196^{\circ} \mathrm{C}\right)$ até o momento da análise.

As dosagens da testosterona e IGF-I foram realizadas por radioimunoensaio, utilizando-se kits comerciais (Gênese Science Ltda), com as amostras testadas em duplicatas. Os coeficientes de variação intra e inter ensaio para a testosterona e IGF-I foram, respectivamente, 1,27 e 2,42; 3,8 e $5,1 \%$.

Ao final do experimento foram abatidos 20 animais (oito do grupo inteiros, sete dos bloqueados e cinco dos castrados), que atingiram peso corporal maior que $480,0 \mathrm{Kg}$, os quais foram utilizados nas avaliações de carcaça. Para avaliação do OVN foram tomadas apenas amostras e cortes com plena visualização do epitélio sensitivo sendo utilizado quatro animais para cada um dos grupos inteiros e castrados e sete dos bloqueados.

Após o abate, foram obtidos os pesos das carcaças quentes sem vísceras, o grau de cobertura de gordura avaliado no frigorífico (acabamento frigorífico) por escala visual de 1 a 5 com base na distribuição de tecido adiposo na superfície da carcaça e os rendimentos de carcaça por meio da divisão do peso da carcaça quente eviscerada pelo peso corporal obtido na fazenda, no dia anterior ao embarque para o frigorífico, multiplicado por 100 (Faria et al., 2009).

Foram ainda avaliados a conformação, os índices de comprimento/profundidade e o grau de cobertura de gordura das carcaças, avaliados por meio de fotografias (acabamento fotografias), utilizando recursos do programa "Image j" (http://www.baixaki.com.br/download/imagej.htm), com as mensurações das imagens realizadas conforme Oliveira (2005).

Ao abate as cabeças foram identificadas na linha de matança para transecção e retiradas dos OVN. Para obtenção de cortes homogêneos do referido órgão foram realizadas a transecções da região nasal ao nível do primeiro pré-molar superior (Salazar et al., 2008), e os fragmentos fixados em líquido de Bouin (Pannocchia et al., 2008).

No laboratório esses fragmentos foram lavados em solução Ringer bicarbonato e, posteriormente, desidratados em concentrações crescentes de etanol. Após esse procedimento, as amostras foram incluídas em glicol metacrilato (Ferreira et al., 2009). Os blocos foram seccionados em ultramicrótomo, obtendo-se cortes de três milímetros de espessura, montados em lâminas histológicas e corados pelo azul de toluidina-0,5\% com borato de sódio a $1,0 \%$. De cada fragmento foram confeccionadas três lâminas com quatro cortes cada.

A arquitetura histológica foi avaliada por meio da mensuração da altura do epitélio sensitivo do OVN utilizando-se microscopia de contraste de fase, sendo as imagens digitalizadas e medidas utilizando-se o programa de análise Motic Images Plus 2.0. As alturas dos epitélios direito e esquerdo do OVN foram mensuradas com base na média das fotografias de quatro mensurações obtidas nos diferentes campos.

Os dados obtidos foram analisados utilizando-se dos recursos do pacote estatístico do Sistema de análises estatísticas e genéticas - SAEG (Ribeiro-Júnior, 2001). O delineamento utilizado foi o inteiramente ao acaso. Para todas as variáveis deste estudo, foram realizados o teste de homogeneidade de Levene e os testes de normalidade de Shapiro-Wilk e Kolmogorov - Smirnov com a correção de Lilliefors, utilizando-se transformações logarítmicas, quando necessário. Posteriormente, foi realizado a ANOVA em todas as variáveis paramétricas e procedeu-se a escolha do teste estatístico para comparação de médias conforme o coeficiente de variação e o número de tratamentos. Para as variáveis que não se enquadravam na distribuição normal, mesmo pós transformação logarítmica, foram aplicados testes não paramétricos para comparação dos ranques (Sampaio, 2002).

Portanto, para análise das diferenças entre os tratamentos para a altura do epitélio sensitivo do OVN, das concentrações séricas de testosterona e IGF-I foi utilizado o teste "t" de Student. Foi utilizado o teste " $\mathrm{t}$ " de Student pareado, para as concentrações séricas hormonais (testosterona e IGF-I), objetivando-se avaliar os efeitos de turno e de coleta em cada tratamento. Sendo que, nesses casos, para utilização do teste "t" de Student as comparações foram realizadas sempre de dois a dois.

Para se avaliar o efeito de tratamento sobre o peso corporal, o ganho de peso médio diário, o índice de comprimento e profundidade da carcaça foi utilizado o teste de SNK. Para análise do efeito de pesagem dentro de cada tratamento para o peso corporal foi utilizado o teste de "t" de Student pareado.

Para as variáveis não paramétricas como acabamento de carcaça avaliada no frigorífico, por fotografias, do rendimento e conformação da carcaça o teste de comparação dos ranques utilizado foi o de Kruskal Wallis, devido a presença de três tratamentos. Foi realizado análise de correlações entre todas as variáveis estudadas, sendo que para as variáveis paramétricas foi realizada a Correlação de Pearson, enquanto para as não paramétricas foi realizada a Correlação de Spearman. Somente os resultados das correlações com valores significativos $(P<0,05)$ foram apresentados no texto. Em todas as variáveis para o teste de comparação das médias e ranques foi considerado o nível de significância de 5\%.

Todos os procedimentos realizados neste estudo estão em conformidade com o comitê de ética em experimentação animal da UFMG (CETEA), segundo o protocolo 159/09.

\section{Resultados e discussão}

Ao início da fase experimental não se registraram diferenças significativas $(P>0,05)$ nos pesos corporais entre os animais dos três grupos experimentais (inteiros, bloqueados e castrados). Já ao final da fase experimental, animais submetidos à obstrução do ducto incisivo (bloqueados) apresentaram maiores pesos corporais e GMD, em relação aos animais castrados $(P<0,05)$, porém não diferiram dos animais inteiros $(P>0,05)$ conforme tabela 1 . 
Tabela 1: Pesos corporais e ganhos de pesos médios diários obtidos no início e final do experimento dos animais dos grupos: controle (inteiros), ductos incisivos bloqueados (bloqueados) e orquiepididectomizados (castrados)

\begin{tabular}{cccc}
\hline $\begin{array}{c}\text { Tratamento/ } \\
\text { Peso corporal }\end{array}$ & $\begin{array}{c}\text { Inteiros } \\
(\mathrm{n}=11)\end{array}$ & $\begin{array}{c}\text { Bloqueados } \\
(\mathrm{n}=10)\end{array}$ & $\begin{array}{c}\text { Castrados } \\
(\mathrm{n}=13)\end{array}$ \\
\hline Início experimento, $\mathrm{Kg}$ & $244,82 \pm 2,77^{\mathrm{a}}$ & $240,22 \pm 11,00^{\mathrm{a}}$ & $242,7 \pm 12,50^{\mathrm{a}}$ \\
Final experimento, $\mathrm{Kg}$ & $494,1 \pm 28,71^{\mathrm{a}}$ & $500,56 \pm 23,64^{\mathrm{a}}$ & $468,31 \pm 21,81^{\mathrm{b}}$ \\
Ganho médio diário, $\mathrm{Kg}$ & $0,521 \pm 0,05^{\mathrm{a}}$ & $0,545 \pm 0,05^{\mathrm{a}}$ & $0,472 \pm 0,03^{\mathrm{b}}$ \\
\hline
\end{tabular}

Letras distintas nas linhas indicam diferenças pelo teste de SNK $(P<0,05)$.

Após 13 e 16 meses do início do experimento (pesagens de fevereiro e maio de 2009), os animais bloqueados apresentaram em média $20,68 \mathrm{Kg}$ e $32,25 \mathrm{~kg}$, respectivamente, a mais que os animais castrados, sendo o peso e o GMD similar aos animais inteiros. A diferença de peso dos animais bloqueados e inteiros (apenas na última pesagem) em relação aos animais castrados está de acordo com Prado et al. (2014), que descrevem que somente no período pós puberal é detectado diferenças na taxa de crescimento entre animais castrados e inteiros, sendo esta diferença atribuída ao efeito anabólico da testosterona (Zhou et al., 2011), uma vez que os níveis deste hormônio foram maiores nos animais bloqueados e inteiros em relação aos castrados (Tab. 3). Da mesma forma a similaridade de peso dos animais inteiros e bloqueados pode ser explicada pelos níveis séricos similares de testosterona, nas amostras coletadas pela manhã.

A castração aumentou os escores de acabamentos das carcaças avaliadas tanto no frigorífico quanto pelas fotografias $(P<0,05)$ e diminuiu o escore de conformação $(P<0,05)$ em relação aos inteiros e aos bloqueados (Tab. 2). Para as demais variáveis não se registraram variações entre os grupos experimentais $(P>0,05)$. Considerando que o acabamento da carcaça avalia o grau de distribuição de gordura (Oliveira, 2005), enquanto a conformação avalia o nível de convexidade muscular (hipertrofia) (Faria et al., 2009), os resultados registrados podem ser atribuídos aos níveis séricos de testosterona, uma vez que este hormônio desvia o metabolismo para formar tecido muscular e ósseo, ativando a absorção renal de nitrogênio e a ação dos osteoblastos (Smith e Saunders, 2011), em detrimento do tecido adiposo. Esses resultados são também confirmados pelos achados de Restle et al. (2000), Zhou et al. (2011) e Miguel et al. (2014).

O bloqueio dos ductos incisivos e a castração não alteraram o peso da carcaça quente eviscerada e o rendimento da carcaça. Com relação ao rendimento de carcaça, a não existência da diferença $(P>0,05)$ entre animais inteiros e castrados em, e está de acordo com os registrados de Restle et al. (2000) e Miguel et al. (2014). No entanto, os primeiros observaram tomizado (castrados) rendimentos de carcaça para inteiros e castrados, respectivamente, de 56,0 e $55,9 \%$, enquanto os segundos 54,7 e $53,9 \%$, sendo valores superiores ao presente estudo, possivelmente a terminação em confinamento realizada nos animais do estudo desses autores possam justificar estas diferenças, já que neste, a terminação foi realizada a pasto.

A altura do epitélio sensitivo do OVN foi maior $(P<0,05)$ nos animais inteiros $(0,17 \pm 0,03$ $\mathrm{mm})$, comparados aos bloqueados $(0,14 \pm 0,03$ $\mathrm{mm})$ e castrados $(0,12 \pm 0,04 \mathrm{~mm})$, que foram semelhantes. Como o epitélio esquerdo e direito do OVN foram semelhantes dentro de cada grupo seus valores foram expressos como média de ambos os lados.

Observou-se que o bloqueio dos ductos incisivos promove alterações no epitélio neuro sensitivo do OVN semelhantes às alterações acarretadas pela castração. Nos animais castrados a redução brusca na concentração de testosterona acarretou em hipo desenvolvimento do epitélio sensitivo do OVN (Baum e Cherry, 2015), enquanto os bloqueados reduziram a entrada de estímulos feromonais pelos ductos incisivos que induziu hipotrofia do epitélio neuro sensitivo do OVN pela interrupção de seu uso (Keverne, 2004).

O perfil sérico de testosterona nos três grupos experimentais, ao longo do experimento, é apresentado na Tab. 3. A partir da segunda coleta, os resultados para os animais castrados foram abaixo dos limites de detecção, por isso seus valores não entraram na avaliação. Verificou-se que os valores registrados estão de acordo com aqueles relatados na literatura. Brito et al. (2007), trabalhando com animais Angus e Angus x Charolês registraram concentração sérica de testosterona variando de 1,0 $\mathrm{ng} / \mathrm{mL}$ na pré puberdade a $11,0 \mathrm{ng} / \mathrm{mL}$ na maturidade sexual, utilizando aplicação de $\mathrm{GnRH}$ antes da coleta do sangue.

Tabela 2: Características de carcaça registradas nos animais dos grupos: controle (inteiros), ductos incisivos bloqueados (bloqueados) e orquiepididec-

\begin{tabular}{cccc}
\hline $\begin{array}{c}\text { Tratamento/ } \\
\text { Variável }\end{array}$ & $\begin{array}{c}\text { Inteiros } \\
(\mathrm{n}=8)\end{array}$ & $\begin{array}{c}\text { Bloqueados } \\
(\mathrm{n}=7)\end{array}$ & $\begin{array}{c}\text { Castrados } \\
(\mathrm{n}=5)\end{array}$ \\
\hline $\begin{array}{c}\text { Acabamento } \\
\text { frigorífico (escore) }\end{array}$ & $1,87 \pm 0,12^{\mathrm{b}}$ & $2,14 \pm 0,14^{\mathrm{b}}$ & $2,8 \pm 0,20^{\mathrm{a}}$ \\
$\begin{array}{c}\text { Conformação (escore) } \\
\text { Acabamento }\end{array}$ & $2,87 \pm 0,1^{\mathrm{a}}$ & $2,7 \pm 0,2^{\mathrm{a}}$ & $2,00 \pm 0,0^{\mathrm{b}}$ \\
$\begin{array}{c}\text { Acabam (escore) } \\
\text { fotografias }\end{array}$ & $1,75 \pm 0,16^{\mathrm{b}}$ & $1,83 \pm 0,17^{\mathrm{b}}$ & $3 \pm 0,0^{\mathrm{a}}$ \\
$\begin{array}{c}\text { Índice comprimento/ } \\
\text { profundidade }\end{array}$ & $0,95 \pm 0,03^{\mathrm{a}}$ & $0,94 \pm 0,05^{\mathrm{a}}$ & $0,92 \pm 0,04^{\mathrm{a}}$ \\
$\begin{array}{c}\text { Peso da carcaça } \\
\text { quente eviscerada }(\mathrm{Kg})^{* *}\end{array}$ & $257,13 \pm 14,09^{\mathrm{a}}$ & $261,54 \pm 11,50^{\mathrm{a}}$ & $253,4 \pm 9,03^{\mathrm{a}}$ \\
$\quad \begin{array}{c}\text { Rendimento de } \\
\text { carcaça }(\%)^{*}\end{array}$ & $51,40 \pm 1,24^{\mathrm{a}}$ & $51,4 \pm 1,70^{\mathrm{a}}$ & $51,7 \pm 0,28^{\mathrm{a}}$ \\
\hline
\end{tabular}

*Letras distintas nas linhas indicam diferenças pelo teste de Kruskal Wallis $(P<0,05) .{ }^{* *}$ Letras distintas nas linhas indicam diferenças pelo teste de SNK $(P<0,05)$. 
Tabela 3: Concentrações séricas de testosterona $(\mathrm{ng} / \mathrm{mL})$ nos períodos da manhã e da tarde nos animais dos grupos: controle (inteiros), ductos incisivos bloqueados (bloqueados) e orquiepididectomizado (castrados)

\begin{tabular}{ccccc}
\hline $\begin{array}{c}\text { Tratamento/ } \\
\text { Coleta }\end{array}$ & Turno & $\begin{array}{c}\text { Inteiros } \\
(\mathrm{n}=6)\end{array}$ & $\begin{array}{c}\text { Bloqueados } \\
(\mathrm{n}=4)\end{array}$ & $\begin{array}{c}\text { Castrados } \\
(\mathrm{n}=6)\end{array}$ \\
\hline \multirow{2}{*}{ Coleta 1 } & Manhã & $1,7 \pm 1,4^{\mathrm{a}, \mathrm{A}, \mathrm{B}}$ & $0,22 \pm 0,15^{\mathrm{a}, \mathrm{C}}$ & $0,34 \pm 0,1^{\mathrm{a}}$ \\
& Tarde & $1,5 \pm 1,2^{\mathrm{a}, \mathrm{B}}$ & $0,8 \pm 0,65^{\mathrm{a}, \mathrm{C}}$ & $0,33 \pm 0,1^{\mathrm{a}}$ \\
Coleta 2 & Manhã & $1,04 \pm 0,3^{\mathrm{a}, \mathrm{B}}$ & $3,11 \pm 1,7^{\mathrm{a}, \mathrm{B}, \mathrm{C}}$ & - \\
& Tarde & $4,04 \pm 2,7^{\mathrm{a}, \mathrm{A}, \mathrm{B}}$ & $0,46 \pm 0,22^{\mathrm{a}, \mathrm{B}, \mathrm{C}}$ & - \\
Coleta 3 & Manhã & $6,5 \pm 2,2^{\mathrm{a}, \mathrm{A}, \mathrm{B}, \mathrm{X}}$ & $7,8 \pm 1,7^{\mathrm{a}, \mathrm{A}, \mathrm{B}, \mathrm{X}}$ & - \\
& Tarde & $1,6 \pm 0,6^{\mathrm{a}, \mathrm{B}, \mathrm{Y}}$ & $1,6 \pm 0,9^{\mathrm{a}, \mathrm{A}, \mathrm{B}, \mathrm{Y}}$ & - \\
Coleta 4 & Manhã & $12,5 \pm 2,1^{\mathrm{a}, \mathrm{A}}$ & $8,5 \pm 3,8^{\mathrm{a}, \mathrm{A}}$ & - \\
& Tarde & $10,3 \pm 1,3^{\mathrm{a}, \mathrm{A}}$ & $5,7 \pm 1,2^{\mathrm{b}, \mathrm{A}}$ & - \\
Coleta 5 & Manhã & $5,5 \pm 2,3^{\mathrm{a}, \mathrm{A}, \mathrm{B}}$ & $3,5 \pm 1,6^{\mathrm{a}, \mathrm{A}, \mathrm{B}}$ & - \\
& Tarde & $8,9 \pm 2,05^{\mathrm{a}, \mathrm{A}}$ & $2,7 \pm 1,3^{\mathrm{b}, \mathrm{A}, \mathrm{B}, \mathrm{C}}$ & - \\
\hline
\end{tabular}

Letras minúsculas nas linhas indicam diferenças $(P<0,05)$ entre tratamento dentro de uma mesma coleta pelo teste "t" de Student. Letras maiúsculas nas colunas indicam diferenças $(P<0,05)$ entre coletas dentro de um mesmo tratamento pelo teste " $t$ " de Student Pareado. As letras $X$ e $Y$ indicam diferenças pelo teste " $t$ " pareado $(P<0,05)$, para se avaliar o efeito de turno dentro de coleta e tratamento, assim como, as ausências destas, indicam ausência de diferenças $(P>0,05)$ entre os turnos.

Foi observado efeito do bloqueio dos ductos incisivos na concentração sérica de testosterona nas coletas quatro e cinco realizadas pela tarde $(P<0,05)(T a b .3)$, sugerindo que o bloqueio dos ductos incisivos impede a entrada de estímulos para o OVN que, por sua vez, reduz os estímulos hipotalâmicos, diminuindo a liberação diária de $\mathrm{GnRH}$, como previamente descrito em roedores sexualmente inexperientes (Keverne, 2004). Em animais Nelore, o OVN exerce importante influência na secreção de testosterona pela tarde, mas não pela manhã, portanto, outros fatores devem estar envolvidos no controle da secreção de testosterona sérica pela manhã nesses animais, em detrimento dos estímulos feromonais para o OVN.

Em touros, a liberação rítmica circadiana de testosterona não tem sido bem estabelecida, sendo que a secreção sérica de testosterona foi descrita como três a quatros picos espontâneos diários (Byrne et al., 2017). No entanto, estudos observaram maiores concentrações pela manhã, sem atribuírem este fato, ao ritmo circadiano da secreção de testosterona (Barbosa et al., 1991; Byrne et al., 2017). No presente estudo, não foi observado diferença entre os turnos durante as coletas discordando dos últimos autores.

No entanto, observou-se um aumento $(P<0,05)$ nas concentrações de testosterona e IGF-1 no período da manhã na terceira coleta (pico da seca e inverno). Os animais bloqueados apresentaram uma redução $(P<0,05)$ na concentração sérica de testosterona no turno da tarde na quarta e quintas coletas em relação aos animais inteiros. Este resultado sugere que o bloqueio da percepção ferormonal, por meio do OVN, promove alteração na secreção sérica de testosterona semelhante àquela acarretada à redução no nível sérico de IGF-I. Brito et al. (2007) descreveram que o eixo somatotrópico pode ser considerado como fator permissivo a liberação da secreção de esteroides em touros. Desta forma, a estimulação ferormonal do OVN também o seria.
Vale destacar que mais estudos são necessários para se confirmar esta hipótese, uma vez que o presente experimento não foi delineado objetivando avaliar esta hipótese.

As diferenças registradas na secreção de testosterona no turno da tarde tanto durante a terceira coleta (período da seca e inverno) quanto na quarta e quinta coleta (efeito de tratamento), permitem aferir que o período da tarde é mais sensível para se observar variações nas concentrações séricas de testosterona ocasionadas por fatores permissivos, quer seja ocasionado pela influencia do eixo somatotrópico, quer seja pelos estímulos olfatórios pela via do OVN. A partir da quarta coleta, foi observado diferença entre os tratamentos na concentração de testosterona sérica, estando de acordo com as observações de Assumpção et al. (2013), no qual foi reportado que a testosterona se torna o principal esteroide masculino secretado pelas células intersticiais de Leydig, visto que à medida que se atinge a fase puberal.

Os resultados observados demonstram que o bloqueio dos ductos incisivos não foi suficiente para promover a variação na concentração sérica de testosterona necessária para resultar em efeitos nas características de carcaças dos animais bloqueados em relação aos inteiros. Contudo, a diferença observada nos níveis séricos de testosterona no período da tarde, por afetar a concentração total diária desse hormônio, nos animais bloqueados sugere que possivelmente em outras condições onde os animais sejam suplementados, o bloqueio do OVN possa melhorar o grau de acabamento da carcaça, visto que foram observadas altas correlações negativas entre essa característica e os níveis séricos de testosterona (Zhou et al., 2011).

Com relação ao IGF-I, registrou-se variação entre as coletas de $200,0 \mathrm{ng} / \mathrm{mL}$ a aproximadamente $550,0 \mathrm{ng} / \mathrm{mL}$. Tais valores estão contidos entre a faixa registrada por Brito et al. (2007), que descreveram variações de 100,0 a aproximadamente 600,0 $\mathrm{ng} / \mathrm{mL}$, em animais Angus e Angus x Charolês a partir da 10 semana de vida até a maturidade sexual. Não se registrou efeito de tratamento, nem tão pouco de turno de coleta, o que permitiu o agrupamento dos dados das diferentes coletas, sem considerar o turno. Observou-se efeito do período de coleta, sendo observado menores concentrações de IGF-I $(P<0,05)$ na terceira coleta nos animais inteiros, bloqueados e castrados $(280,6 \pm 10,9 ; 254 \pm 44,5$ e $248,6 \pm 27,6$, respectivamente), provavelmente devido ao pico do período de seca (julho), onde se tem o pior momento da qualidade das forragens, visto que este hormônio está associado com o nível energético da dieta (Prado et al., 2014).

\section{Conclusão}

Conclui-se que a obstrução dos ductos incisivos reduziu a entrada de estímulos sensoriais para o órgão vomeronasal, que por sua vez, promoveu alteração na concentração sérica de testosterona, sem alterar o ganho de peso dos animais, porém, não promoveu melhoria no acabamento e no rendimento de carcaça, nas condições deste estudo. 


\section{Agradecimentos}

Aos funcionários, ao Nilson A. de Azevedo e proprietário da Faz. Santo Antônio das Granjas Reunidas pela colaboração na parte de campo e pelo fornecimento dos animais. À Janine C. Ivo e ao Prof. Cândido C. Coimbra, pela colaboração nas análises de radioimunoensaio. Ao CNPq pela concessão da bolsa e pelo total apoio financeiro à pesquisa.

\section{Referências}

ASSUMPÇÃO, T.I.; SOUZA, M.A.; ALBERTON, C.; PALLAORO, R.; KITAGAWA, C.; SILVA, N.A.M. Características reprodutivas de machos bovinos da raça Nelore da fase pré-púbere à maturidade sexual. Revista Brasileira de Ciência Veterinária, v.20, n.3, p.148 - 154, 2013.

BARBOSA, R.T.; ALENCAR, M.N.; BARBOSA, P.F.; FONSECA, V.O. Comportamento sexual de touros das raças Canchim e Nelore. Revista Brasileira de Reprodução Animal, v.15, n.3-4, p.151 - 157, 1991.

BAUM, M.J.; CHERRY, J.A. Processing by the main olfactory system of chemosignals that facilitate mammalian reproduction. Hormones and behavior, v.68, p.53 - 64, 2015.

BOOTH, K.K.; KATZ, L.S. Role of the vomeronasal organ in neonatal offspring recognition in Sheep. Biology of Reproduction, v.63, n.3, p.953 - 958, 2000.

BRITO, L.F.C.; BARTH, A.; RAWLINGS, N.; WILDE, R.E.; CREWS-JR, D.H.; MIR, P.S.; KASTELIC, J.P. Circulating metabolic hormones during the peripubertal period and their association with testicular development in bulls. Reproduction in Domestic Animals, v.42, n.5, p.502 - 508, 2007.

BYRNE, C.J.; FAIR, S.; ENGLISH, A.M.; URH, C.; SAUERWEIN, H.; CROWE, M.A.; KENNY, D.A. Effect of breed, plane of nutrition and age on growth, scrotal development, metabolite concentrations and on systemic gonadotropin and testosterone concentrations following a $\mathrm{GnRH}$ challenge in young dairy bulls. Theriogenology, v.96, p.58 - 68, 2017.

FARIA, C.U.D.; MAGNABOSCO, C.D.U.; ALBUQUERQUE, L.G.D.; BEZERRA, L.A.F.; LÔBO, R.B. Estimativas de correlações genéticas entre escores visuais e características de carcaça medidas por ultrassonografia em bovinos Nelore utilizando modelos bayesianos linear-limiar. Revista Brasileira de Zootecnia, v.38, n.11, p.2144 - 2151, 2009.

FERREIRA, A.; ROSA, A.B.D.S.; MEHANNA, M. Organização celular dos testículos em Hylidae e leptodactylidae, no Pantanal (Estado do Mato Grosso do Sul, Brasil). Acta Scientiarum: Biological Sciences, v.31, n.4, p.447 - 452, 2009.

GÖKDAL, Ö.; ATAY, O.; ÜLKER, H.; KAYAARDI, S.; KANTER, M.; DEAVILA, M.D.; REEVES, J.J. The effects of immunological castration against $\mathrm{GnRH}$ with recombinant OL protein (OvalbuminLHRH-7) on carcass and meat quality characteristics, histological appearance of testes and pituitary gland in Kivircik male lambs. Meat Science, v.86, n.3, p.692 - 698, 2010.

KEVERNE, E.B. Importance of olfactory and vomeronasal systems for male sexual function. Physiology \& Behavior, v.83, n.2, p.177 - 187, 2004.

LOPES, F.G.; GUIMARÃES, J.D.; COSTA, E.P.; CARVALHO, G.R.; NETO, T.M. Avaliação andrológica por pontos e comportamento sexual em touros da raça Nelore. Revista Brasileira de Zootecnia, v.38, n.6, p.1018 - 1025, 2009.

MIGUEL, G.Z.; FARIA, M.H.; ROÇA, R.O.; SANTOS, C.T.; SUMAN, S.P.; FAITARONE, A.B.; SU, L.S. Immunocastration improves carcass traits and beef color attributes in Nellore and Nellore $x$ Aberdeen Angus crossbred animals finished in feedlot. Meat Science, v.96, n.2, p.884 - 891, 2014.
OLIVEIRA, A.L. Búfalos: produção, qualidade de carcaça e de carne. Alguns aspectos quantitativos e nutricionais para promoção do melhoramento genético. Revista Brasileira de Reprodução Animal, v.29, n.2, p.122 - 134, 2005.

PADUA, J.T.; OLIVEIRA, M.P. de; SILVA, L.A.F. da; VIEIRA, L. da S.; FIGUEIREDO, E.J.; MORALES, D.C.S.P.; CARRIJO, L.H.D.; MARTINS, F. do C. Efeito de métodos de castração e do uso de vermífugos sobre o ganho em peso de bovinos mestiços leiteiros. Ciência Animal Brasileira, v.4, n.1, p.33 - 43, 2003.

PANNOCCHIA, M.A.; BORELLA, M.I.; CAMARGO, A.M. de; GILIO, J.M.; SILVA, C.A. da. Estratégia efetiva de fixação do testículo de ratos Wistar para avaliar os parâmetros morfológicos e morfométricos do epitélio seminífero. ConScientia e Saúde, v.7, n.2, p.227 - 233, 2008.

PRADO, I.N.; CAMPO, M.M.; MUELA, E.; VALERO, M.V.; CATALAN, O.; OLLETA, J.L.; SAÑUDO, C. Effects of castration age, dietary protein level and lysine/methionine ratio on animal performance, carcass and meat quality of Friesian steers intensively reared. Animal, v.8, n.9, p.1561 - 1568, 2014.

RESTLE, J.; VAZ, F.N.; FEIJÓ, G.L.D.; BRONDANI, I.L.; ALVESFILHO, D.C.; BERNARDES, R.A.C.; FATURI, C.; PACHECO, P.S. Características de carcaça de bovinos de corte inteiros ou castrados de diferentes composições raciais Charolês x Nelore. Revista Brasileira de Zootecnia, v.29, n.5, p.1371-1379, 2000.

RESTLE, J.; GRASSI, C.; FEIJÓ, G.L.D. Desenvolvimento e rendimento de carcaça de bovinos inteiros ou submetidos a duas formas de castração, em condições de pastagem. Revista da Sociedade Brasileira de Zootecnia, v.25, n.2, p.324 - 333, 1996.

RIBEIRO-JÚNIOR, J.I. Análise estatística no SAEG (Sistemas de análises estatísticas e genéticas). Viçosa, MG: Editora UFV, 2001. 301p.

ROTTA, P.P.; PRADO, R.D.; PRADO, I.D.; VALERO, M.V.; VISENTAINER, J.V.; SILVA, R.R. The effects of genetic groups, nutrition, finishing systems and gender of Brazilian cattle on carcass characteristics and beef composition and appearance: a review. Asian-Australasian Journal of Animal Sciences, v.22, n.12, p.1718 - 1734, 2009.

SALAZAR, I.; SÁNCHEZ-QUINTERO, P.; ALEMAÑ, N.; PRIETRO, D. Anatomical, immnunohistochemical and physiological characteristics of the vomeronasal vessels in cows and their possible role in vomeronasal reception. Journal of Anatomy, v.212, n.5, p.686 - 696, 2008.

SAMPAIO, I.B.M. Estatística aplicada à experimentação animal. 2ed. Belo Horizonte, MG: FEPE MVZ, 2002. 265p.

SMITH, L.B.; SAUNDERS, P.T. The skeleton: the new controller of male fertility? Cell, v.144, n.5, p.642 - 643, 2011.

VYAS, S.; BRIANT, C.; CHEMINEAU, P.; DANVIC, C. Le; NAGNAN-LE MEILLOUR, P. Oestrus pheromones in farm mammals, with special reference to cow. Indian Journal of Animal Sciences, v.82, n.3, p.256 - 267, 2012.

ZHOU, Z.K.; GAO, X.; LI; J.Y.; CHEN, J.B.; XU, S.Z. Effect of castration on carcass quality and differential gene expression of longissimus muscle between steer and bull. Molecular Biology Reports, v.38, n.8, p.5307 - 5312, 2011. 